\title{
Reinforced concrete confinement coefficient estimation using soft computing models
}

\author{
Mohammed H. Mohana ${ }^{1}$ \\ ${ }^{1}$ College of civil engineering, University of Anbar, Ramadi, Iraq
}

\begin{abstract}
Infrastructure vulnerability toward seismic lateral loading within high seismicity has received massive attention by structural engineers and designers. This is for the purpose to provide a reliable alternative material that strengthening the bending and shear of slabs, columns and reinforced concrete (RC). Despite the utilized approaches of strengthening the concrete structure based on fiber reinforced polymers (FRP) is considerably new technique, exploring more reliable and robust methodologies is the motive of scholars for better structural behaviour understanding. In the current research, two soft computing models called artificial neural network (ANN) and support vector regression (SVR) are applied to predict lateral confinement coefficient $\left(K_{s}\right)$. The models are developed based on gathered dataset from open source researches for the lateral confinement coefficient of columns wrapped with carbon FRP (CFRP) and their corresponding parameters including column width, length and thickness $(b, h$ and $t$ $\mathrm{mm})$, column radius $(r \mathrm{~mm})$, compressive strength of concrete $\left(f_{c}^{\prime}\right)$ and elastic modulus $\left(E_{F R P}\right)$. Results indicated the superiority of the ANN model for predicting $K_{s}$ over the SVR model. The application of the soft computing showed an optimistic approach for the structural lateral confinement coefficient determination.
\end{abstract}

\begin{tabular}{ll}
\hline Keywords: & $\begin{array}{l}\text { Lateral confinement coefficient, structural engineering, soft computing, compressive } \\
\text { strength }\end{array}$ \\
\hline
\end{tabular}

\section{Corresponding Author: Mohammed Hmood Mohana}

Mohana,

Departement of civil engineering,

University of Anbar,

E-mail: mhm1961mhm@uoanbar.edu.iq

\section{Introduction}

The existing reinforced concrete (RC) structures within the earthquake prone regions all around the world exhibit insufficient seismic resistance owing to the continuous updated structural design conditions [1]. The previous earthquake episodes had been shown to have severe impact on the existing buildings because the structural elements of such buildings (such as the slabs, the beams, the columns and the shear walls) have poor seismic resistance [2], [3]. Some of the early studies were focused on the observed performance of buildings, damage statistics, as well as the patterns of different configurations of RC construction [4], [5]. Therefore, several changes have been made on the seismic model codes over the last few decades based on the experience from the previous major earthquake episodes. Among the major code changes was on improving the seismic resistance of the current RC structures by using Performance-Based (PB) design principles that will permit the use of the structures' strength \& displacement ductility reserve [6].

Numerous studies have previously strived to develop reliable approaches and alternatives materials for improving the ability of structural elements in bending and shear [7], [8]. Lateral confinement with fiberreinforced polymer (FRP) has been recommended for implementation in columns under seismic loading as an efficient method of retrofitting the deformable regions of columns with inappropriate confinement [9]. Hence, FRP -reinforcement approach is considered an alternative retrofitting technique for increasing compressive strengths and deformation capacities. Using FRP in columns, various novel approach but has been in use for some years now. As such, various studies have analytically and experimentally focused on the assessment of the stress-strain behavior and axial load capacity of FRP-reinforced concrete. These studies on RC columns have proved the capability of FRP jackets to avoid early concrete failure and steel bars buckling, leading to 
the enhancement of the energy absorption capacity and axial strength of wrapped column under different loadings (cyclic and static). Literature evidence suggests the presence of several confinement models for the prediction and assessment of the non-linear behavior of FRP-reinforced RC columns.

During the design of RC columns, one of the important aspects is the proper and rapid estimation of the stress-strain relationships for the FRP-reinforced RC columns [10]. For this purpose, several analytic methodologies have been proposed and established for the designing and setting up of FRP-reinforced RC columns [11]. However, these models are complicated in terms of implementation in computer applications due to the effect of various factors that reflect the constitutive behavior of concrete, such as the properties of the composite materials, the column size effect, as well as the differences in confinement stiffness during loading. Sometimes, the calculated values have differed from the predicted values of the non-linear behavior of confined columns [12]. A new era of simulation methodologies called Artificial intelligence (AI) models has been explored as reliable alternative methods for prediction [13].

Artificial intelligence models have been proven capable in diverse engineering applications [14]-[18]. More particularly, for structural and material engineering sciences [19]-[21]. For instance, the feasibility of ANN in forecasting the shear capability of FRP-reinforced RC beams has been investigated [22] and found more accurate compared to guideline equations based on the experimental findings. Similarly, Naser et al. focused on the alternative method of predicting the fire resistance of CFRP plate-reinforced RC T-beams [23]. From the result, the ANN model was found as a capable tool for analysis and designing of CFRP plates-reinforced RC beams under different thermal loadings. Furthermore, Mashrei et al. suggested a backpropagation neural network (BPNN) model that considered 150 experimental data from different sources for the prediction of the bond strength of concrete-to- FRP joints [24]. From the results, the BPNN model was found as an efficient way of estimating bond strength compared to the existing analytical methods. The literature review has evidenced the capacity of the soft computing models in modeling material and structural engineering problems [25]-[28].

In structural engineering, the modeling of highly dynamic systems is known to be a difficult task due to the complexity in their performance and their variation in different loading and operational conditions. Despite the capability of several traditional models to provide good info about the mechanism, their application to a specific structural system requires much effort. Hence, SC models have found application in modeling numerous complex systems due to their ability to explain the non-linear mechanism between the parameters in such systems. The potential benefits of soft computing techniques have been noted by several studies; hence, the aim of the current research is to discover the capacity of two AI models (i.e., ANN and SVR) in modeling the lateral confinement coefficient of CFRP-reinforced $\mathrm{RC}$ rectangular columns.

\section{Experimental data explanation}

This study employed several experimental data of both rectangular and square FRP-reinforced columns previously investigated by numerous scholars [29]-[41] for modeling the imorovement in the strength of CFRP-reinforced RC rectangular columns using ANN and SVR models. The mechanical and geometrical corresponding parameters of the FRP-reinforced including column width, length and thickness $(b, h$ and $t$ $\mathrm{mm}$ ), column radius $(r \mathrm{~mm})$, compressive strength of concrete $\left(f_{c}^{\prime}\right)$ and elastic modulus $\left(E_{F R P}\right)$, were utilized to build the predictive models. A total of 163 experimental dataset on the mechanical and geometrical characteristics was selected.

\section{Applied soft computing models}

\subsection{Artificial neural network (ANN)}

Neural network is computational system of interconnected neurons that trade information between each other; these connections have weights and such weights are changeable based on the prediction accuracy, thereby making NN adaptive and conferring them the ability to learn [42]. During the training of a NN, the connection weights between the elements can be adjusted to make the neural network perform a specific function [43]. The network is adjusted in a manner that a given input will give a specific output as depicted in Figure 1. The network is prepared based on the evaluation of the output of the network with the target until a perfect match 
is achieved between the output and the target output). The connections (inputs) are weighted and these weights are called synaptic weights; the weights are associated with the connections and are multiplied with the connection travelling along each signal. Neural networks can be trained to execute complex tasks such as pattern recognition, function approximation, vision and speech recognition, regression analysis, and control systems [44].

The backpropagation neural network (BPNN) is a common method for both regression analysis and practical implementations. The BP algorithm consists of different layers; the first layer serves as the input layer while the last layer serves as the output layer. Both layers are connected by the hidden layer and is composed of processing units called neurons. The layers are involved in receiving information, processing such information, and producing the outputs. The complexity of a problem determines the number of hidden layers that will be contained in the network; at first, the number of hidden layers in the network is small but the network performance can be optimized by optimizing the number of hidden neurons.

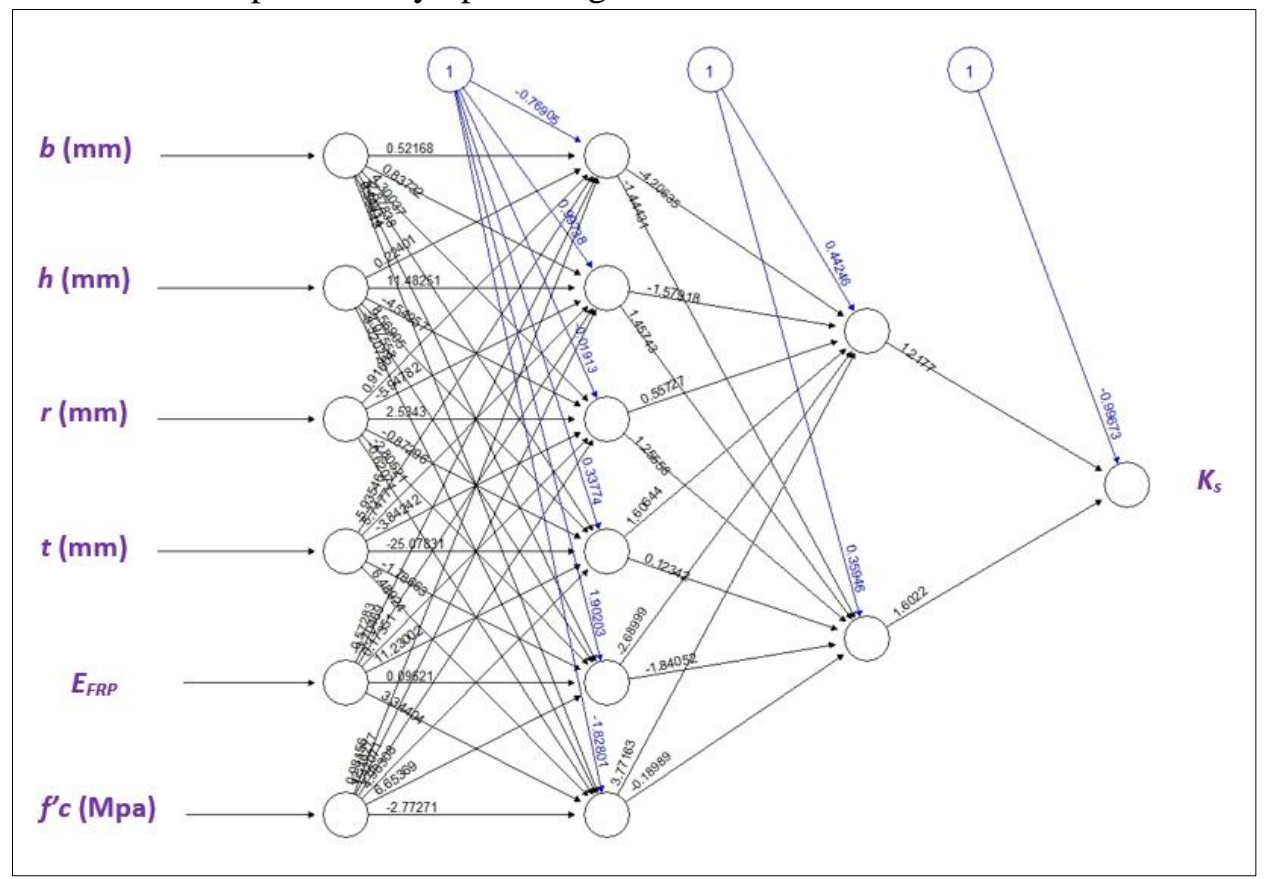

Figure 1. The structure of the input parameters and the targeted parameter using the artificial neural network model.

\subsection{Support vector regression (SVR)}

SVR model is based on the stastistical theory that first introduced by Vapnik [45]. It is an effective method for improving generalization performance and obtaining unique and globally optimal solution. SVR is commonly used for regression estimation and pattern recognition but with the recent $\varepsilon$-insensitive loss function by Vapnik [46]. SVR can be employed to solve time-series and non-linear regression estimations [47], [48]. SVR model basically aims at structural risk minimization (SRM)-based minimization the generalization error upper bound [49]. SVR aims at mapping the input variable (i.e., predictors) and the output variables (i.e., predictand) with non-linear high-dimensional (HD) feature space, this is to perform linear regression in this HD feature space. Mathematically, the expression of the regression model is as follows: $y=f(x)+e$, where $x$ is the input parameters of the studied problem while $y$ is the output parameter $\left(K_{s}\right)$; both functions are expressed in the HD feature space; $e$ represents the independent random error [50].

For a given dataset, $G=\left\{\left(x_{i}, y_{i}\right), I=1,2, \ldots, l\right\}$, where $l$ is the training data size, $x_{i}$ is the input value, and $y_{i}$ is the output value. SVR strives to establish the function that will give guarantee a deviation of e magnitude from the real output. The optimum regression function is computed as follows:

$$
f(x)=\omega \cdot \varphi(x)+b
$$

where $x$ represents the vector weight, $b$ is the scalar threshold, while $\varphi(x)$ is the HD feature spaces that are mapped nonlinearly from the input space $x$. Coefficients $\omega$ and $b$ are estimated via the minimization of the regularized risk function. The systematic SVR model structure is presented in Figure 2. 


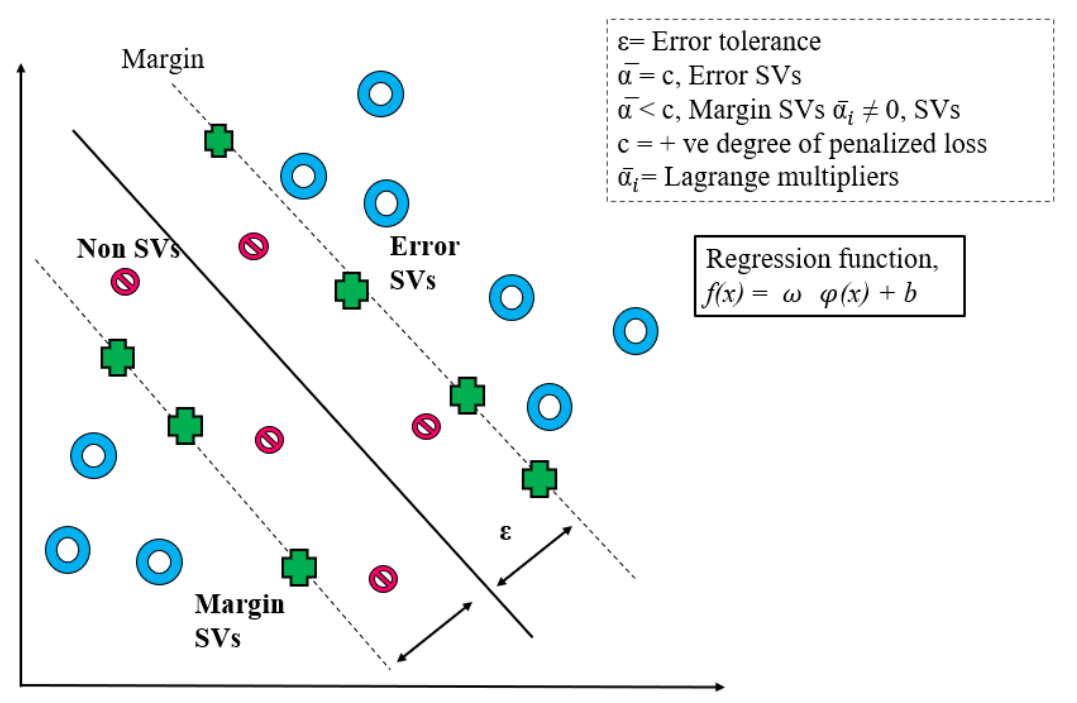

Figure 2. The SVR model mechanism.

\subsection{Prediction evaluation indicators}

The developed ANN and SVR prediction models were assessed using several statistical performance indictators including:

$$
\begin{aligned}
\text { Mean absolute percantge error: } M A P E & =\frac{100}{N} \sum_{i=1}^{N}\left|\frac{K_{s_{\text {exp }}}-K_{s_{\text {pred }}}}{K_{s_{\text {exp }}}}\right| \\
\text { Root mean square error: } R M S E & =\sqrt{\frac{\sum_{i=1}^{N}\left(K_{s_{\text {exp }}}-K_{s_{\text {pred }}}\right)^{2}}{N}} \\
\text { Mean absolute error: } M A E & =\frac{\sum_{i=1}^{N}\left|K_{s_{\text {exp }}}-K_{s_{\text {pred }}}\right|}{N} \\
\text { Root mean square relative error: } R M S R E & =\sqrt{\frac{1}{N} \sum_{i=1}^{N}\left(\frac{K_{s_{\text {exp }}}-K_{\text {spred }}}{K_{s_{\text {exp }}}}\right)^{2}} \\
\text { Nash }- \text { Sutcliffe Efficiency: } N S E & =1-\frac{\sum_{i=1}^{N}\left(K_{\text {exp }_{\text {exp }}}-K_{s_{\text {pred }}}\right)^{2}}{\sum_{i=1}^{N}\left(K_{s_{\text {exp }}}-\overline{K_{s_{\text {exp }}}}\right)^{2}}
\end{aligned}
$$

where $K_{s_{\text {exp }}}$ and $K_{s_{\text {pred }}}$ are the observed and predicted $K_{s} . \overline{K_{s e x p}}$ is the mean observed dataset. N is the number of samples for the training and testing phases.

\section{Results and disccusion}

The current phase is covered the prediction capacity of the $K_{s}$ over the training and testing phases using several statistical performance indicators and graphical presentations. The ANN and SVR models were constructed based on several related parameters and structured based on the parameters charachtristics. Three different mdoeling scenarions were built based on the types of the input parameters. The first input combination was incipated for all parameters $\left(f_{c}^{\prime}, E_{F R P}, b, h, r, t\right)$, the second input combination was incorporated only the $\left(f_{c}^{\prime}\right)$ while the third input combination structured based on $\left(f_{c}^{\prime}\right.$ and $\left.E_{F R P}\right)$. Prior the presentation of the prediction results. It is essential to examine the correlation analysis between the predictors and the predictand. Based on the reported correlation statistical results in Table 1, all parameters have substantial correlation toward the $K_{s}$. However, the column length revealed the minimum value of correlation.

Table 1. The correlation statistics between the targeted $K_{s}$ and the other parameters.

\begin{tabular}{|l|l|l|l|l|l|l|l|}
\hline & $\boldsymbol{b}(\mathrm{mm})$ & $h(\mathrm{~mm})$ & $\boldsymbol{r}(\mathrm{mm})$ & $\boldsymbol{t}(\mathrm{mm})$ & $\begin{array}{l}\boldsymbol{E}_{F R P} \\
(\mathrm{MPa})\end{array}$ & $\boldsymbol{f}_{c}^{\prime}$ & $\boldsymbol{K}_{s}$ \\
\hline
\end{tabular}




\begin{tabular}{|l|l|l|l|l|l|l|l|}
\hline $\boldsymbol{b}(\boldsymbol{m m})$ & 1 & & & & & & \\
\hline $\boldsymbol{h}(\boldsymbol{m m})$ & 0.423386 & 1 & & & & & \\
\hline $\boldsymbol{r}(\boldsymbol{m m})$ & 0.637752 & 0.241128 & 1 & & & & \\
\hline $\boldsymbol{t}(\boldsymbol{m m})$ & 0.343928 & 0.323334 & 0.242014 & 1 & & & \\
\hline $\boldsymbol{E}_{\boldsymbol{F R P}}(\boldsymbol{M P a})$ & -0.1472 & -0.10935 & -0.03 & -0.66113 & 1 & & \\
\hline $\boldsymbol{f}_{\boldsymbol{c}}^{\prime}$ & -0.31764 & -0.0754 & -0.11855 & 0.168722 & -0.24404 & 1 & \\
\hline $\boldsymbol{K}_{\boldsymbol{s}}$ & 0.292655 & -0.01374 & 0.305654 & 0.126099 & 0.267132 & -0.51922 & 1 \\
\hline
\end{tabular}

The learning process of the applied predictive models was demonstrated based on $80 \%$ of the total dataset. Whereas, the remaining $20 \%$ was used to validate the constructed learning network as testing phase. Table 2 and 3 were indicated the prediction results of the $K_{s}$ using ANN and SVR model over the training and testing phases, respectively. In accordance the attained prediction results. The training phase was conducted remarkably with minimum values of RMSE (0.16 and 0.32) for ANN and SVR in that order using all the input parameters (Model 1) (Table 2). The same superiority of prediction was observed for the first input combination and for ANN model over the testing phase. The minimum RMSE and MAE were 0.50 and 0.33. On the other hand, the prediction performance of the SVR model attained lower capacity with RMSE-MAE values $(0.32-0.17$ and $0.56-0.29)$.

Table 2. The statistical performance results over the training phase for ANN and SVR models.

\begin{tabular}{|l|c|c|c|c|c|}
\hline Models & MAPE & RMSE & MAE & RMSRE & NSE \\
\hline ANN & & & & & \\
\hline Model 1 & 0.06246 & 0.16206 & 0.10764 & 0.0886 & 0.94396 \\
\hline Model 2 & 0.21018 & 0.52731 & 0.36999 & 0.28495 & 0.40668 \\
\hline Model 3 & 0.20877 & 0.52291 & 0.3697 & 0.28003 & 0.41653 \\
\hline SVR & & & & & \\
\hline Model 1 & 0.08377 & 0.32644 & 0.17891 & 0.12314 & 0.77929 \\
\hline Model 2 & 0.19313 & 0.61002 & 0.38798 & 0.24985 & 0.22928 \\
\hline Model 3 & 0.18102 & 0.61402 & 0.37674 & 0.23678 & 0.21913 \\
\hline
\end{tabular}

Table 3. The statistical performance results over the testing phase for ANN and SVR models.

\begin{tabular}{|l|c|c|c|c|c|}
\hline & MAPE & RMSE & MAE & RMSRE & NSE \\
\hline ANN & & & & & \\
\hline Model 1 & 0.17221 & 0.50027 & 0.33869 & 0.24634 & 0.63756 \\
\hline Model 2 & 0.25415 & 0.75823 & 0.53865 & 0.30652 & 0.16741 \\
\hline Model 3 & 0.26198 & 0.75312 & 0.54335 & 0.31437 & 0.17859 \\
\hline SVR & & & & & \\
\hline Model 1 & 0.13364 & 0.56834 & 0.29331 & 0.21105 & 0.50116 \\
\hline Model 2 & 0.19622 & 0.64558 & 0.4127 & 0.23704 & 0.35635 \\
\hline Model 3 & 0.24369 & 0.7935 & 0.50138 & 0.31378 & 0.0276 \\
\hline
\end{tabular}

For better visualization, the testing phase was demonstrated graphically for both applied models and for the three-input combination (Figure 3: the observed and predicted values, Figure 4: the relative error percentage and Figure 5: the Taylor diagram). Apparently, the first input combination that incorporated all related 
parameters was the perfect scenario to structure the prediction learning process matrix. On the same manners, Figure 6: the observed and predicted values, Figure 7: the relative error percentage and Figure 8: the Taylor diagram, were indicated the prediction results of the SVR model. Evidently, the first combination provided the best prediction; however, the capacity of the ANN model revealed better results.
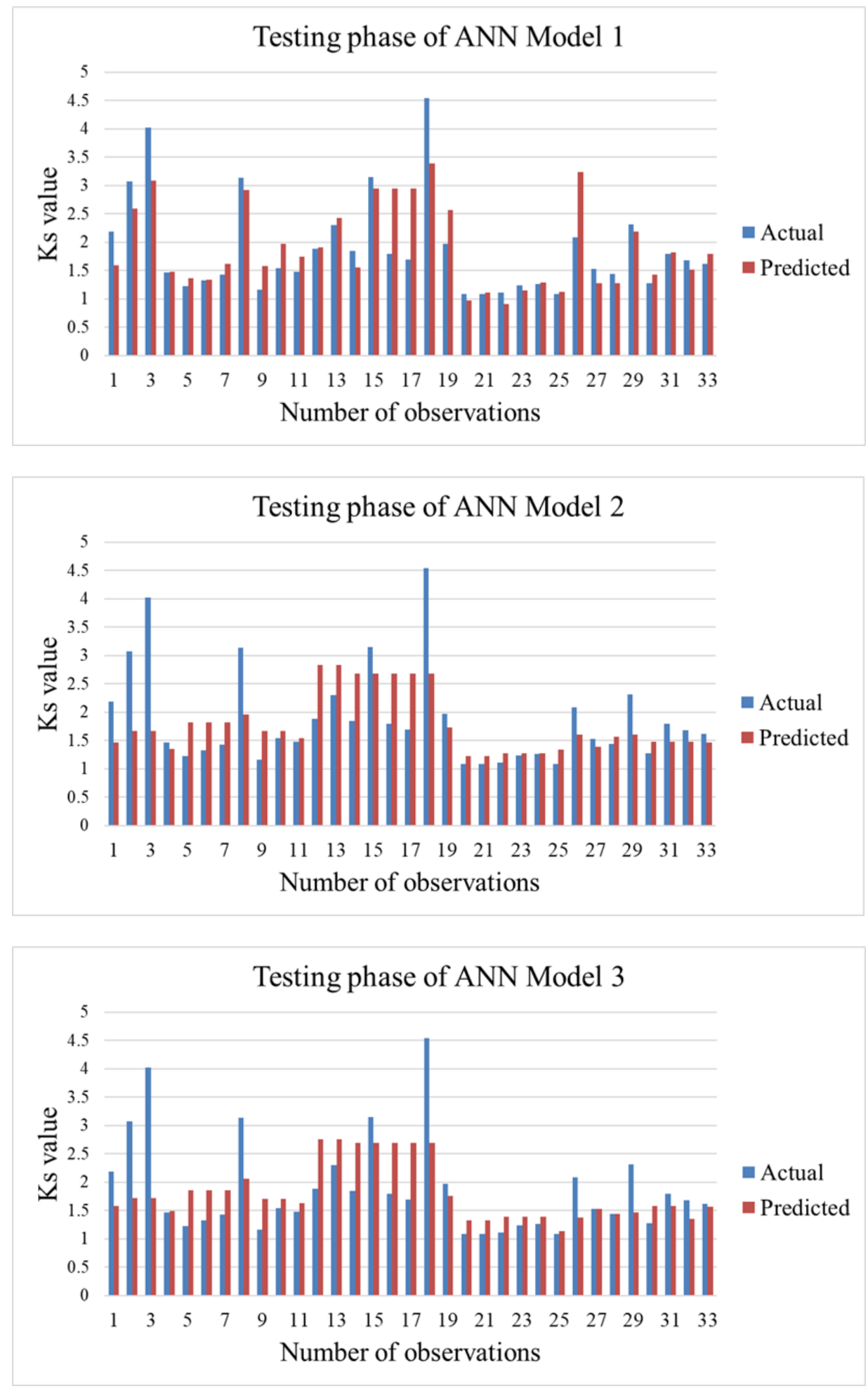

Figure 3. The observed and predicted values of the $K_{s}$ using ANN model for all the modeling scenarions over the testing phase. 


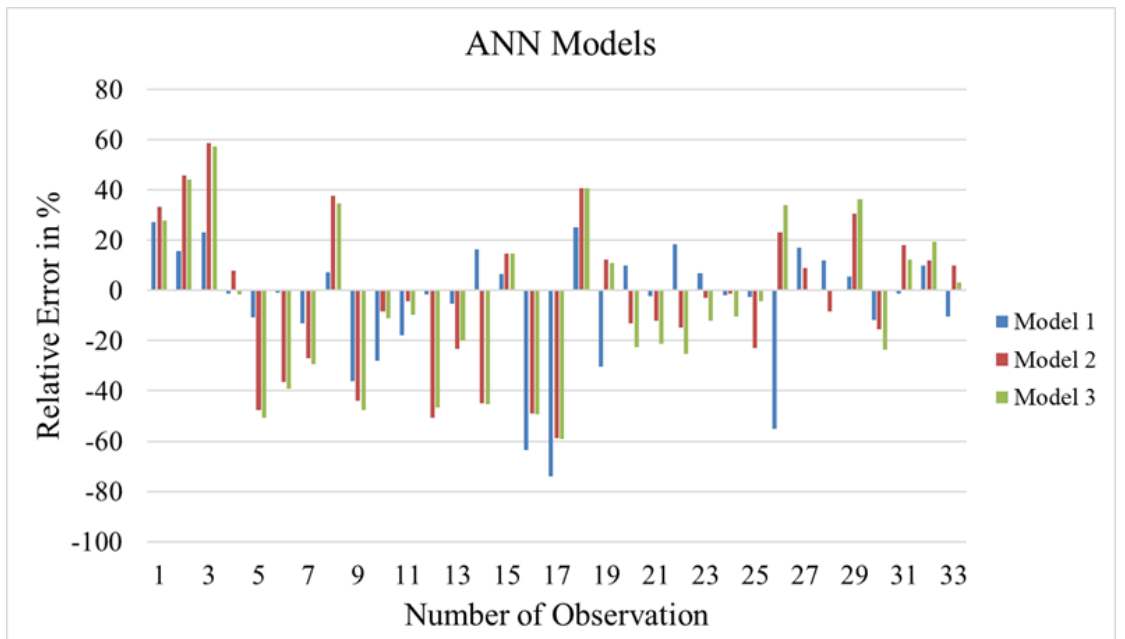

Figure 4. The relative error percentage between the observed and predicted values of the $K_{s}$ using ANN model for all the modeling scenarions over the testing phase.

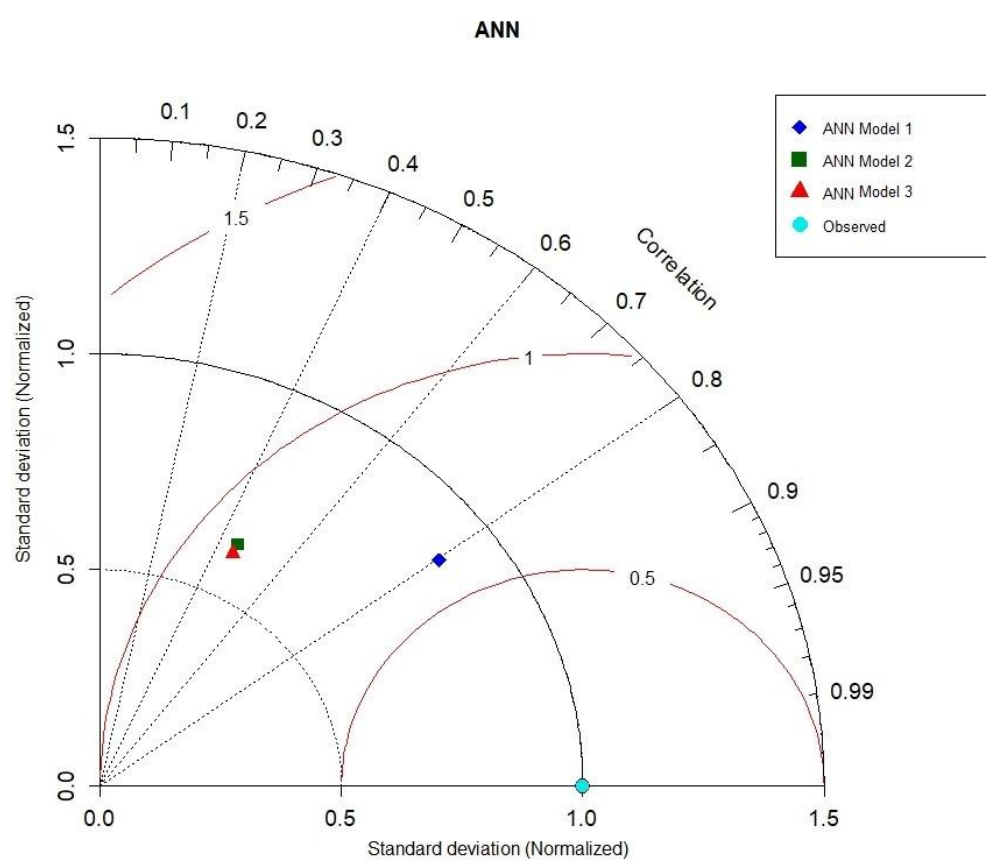

Figure 5. Taylor diagram presentation of the observed and predicted values of the $K_{s}$ using ANN model for all the modeling scenarions over the testing phase.

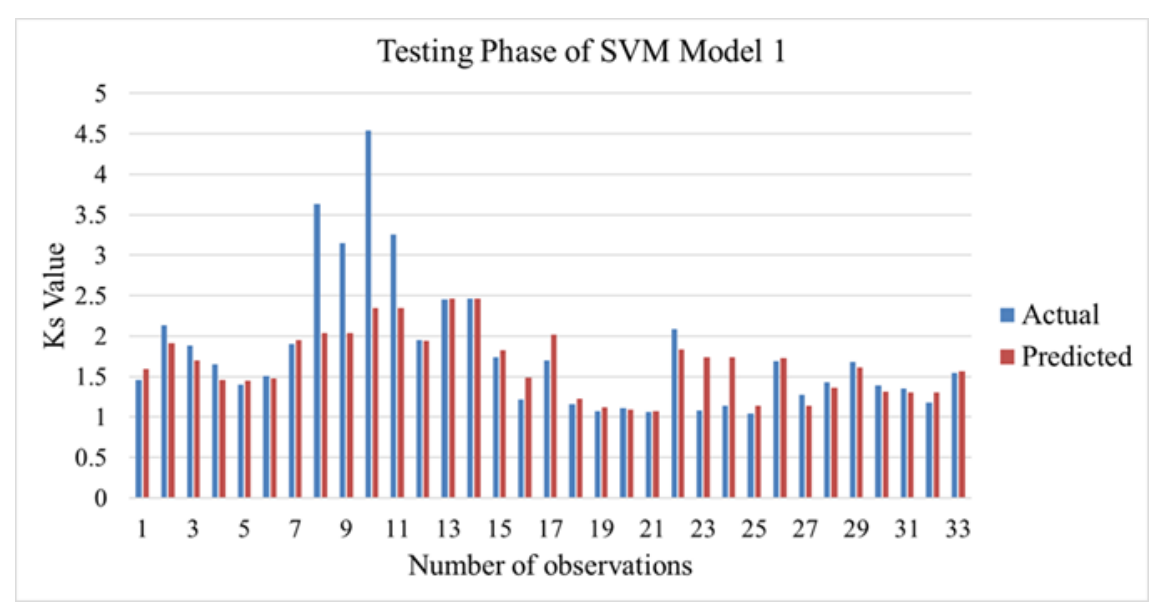



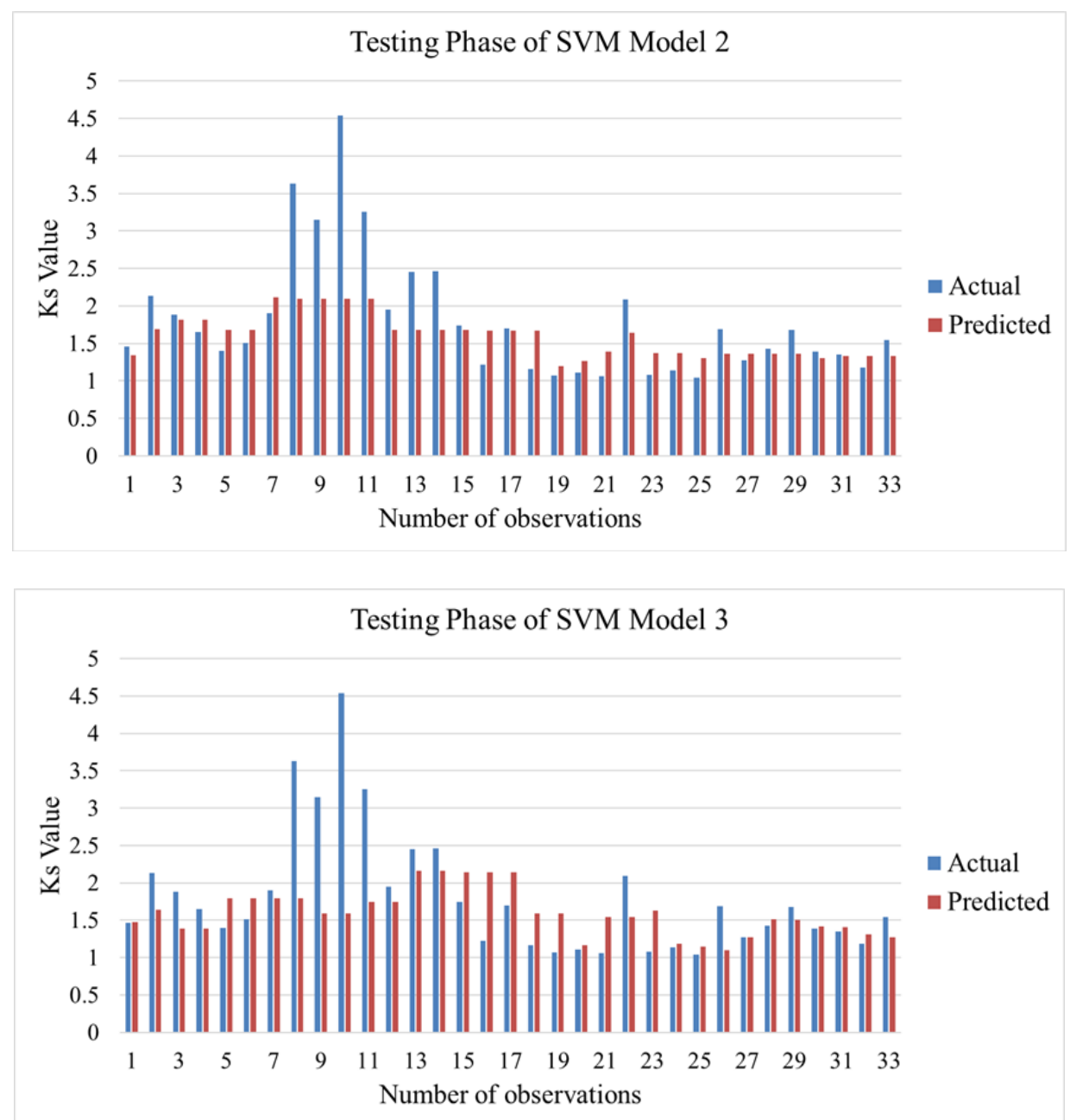

Figure 6. The observed and predicted values of the Ks using SVR model for all the modeling scenarions over the testing phase.

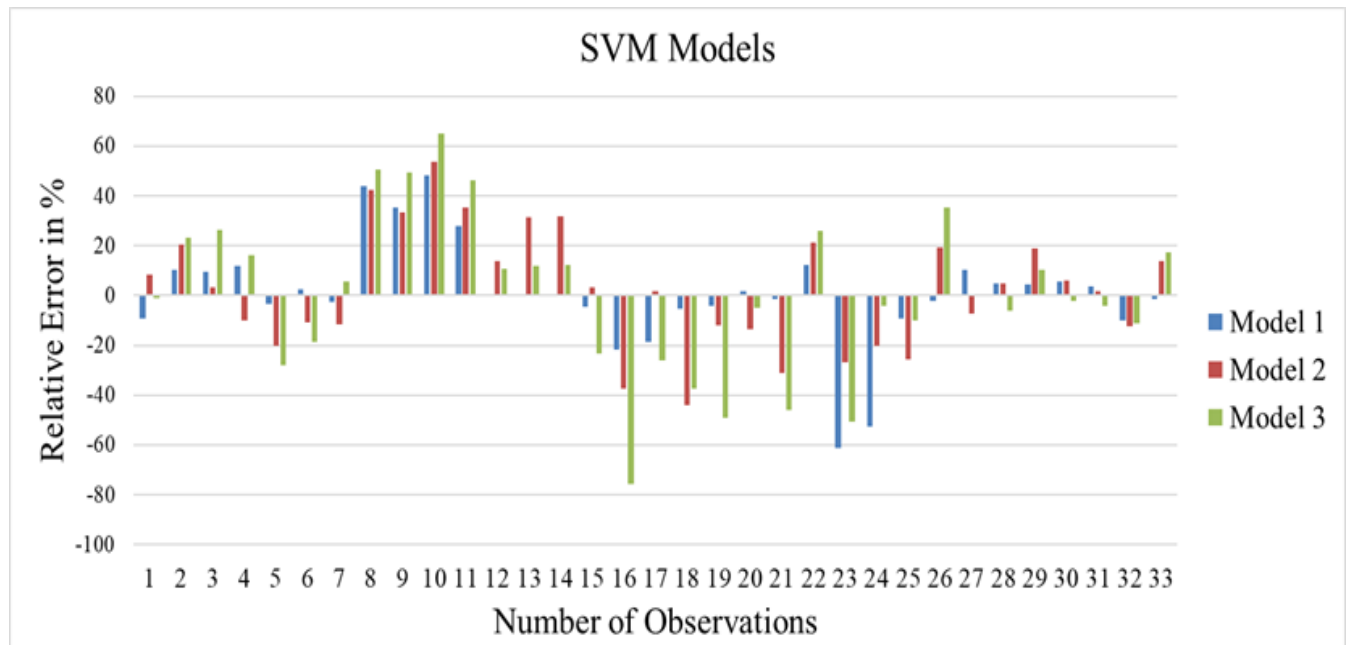

Figure 7. The relative error percentage between the observed and predicted values of the Ks using SVR model for all the modeling scenarions over the testing phase. 


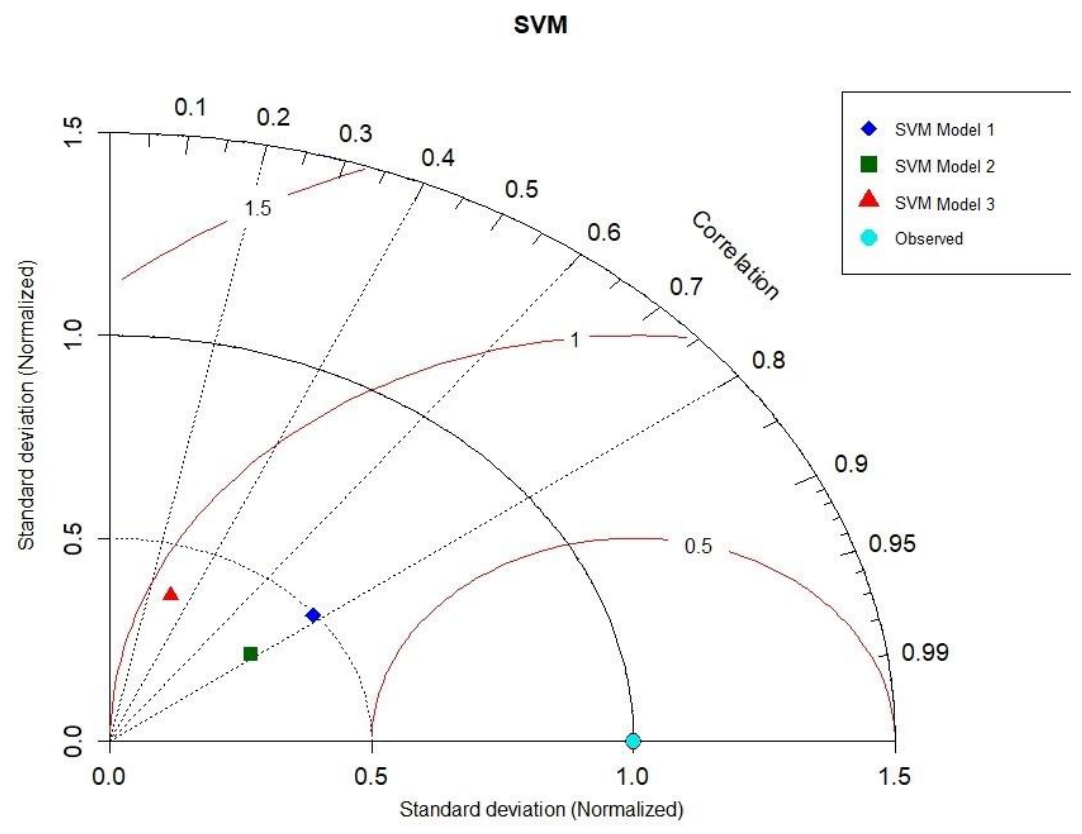

Figure 8. Taylor diagram presentation of the observed and predicted values of the $K_{\mathrm{s}}$ using SVR model for all the modeling scenarions over the testing phase.

The prediction of the applied ANN and SVR models were demonstrated a kind of limitation based on the prediction results. Hence, the predictability performance of those model can be enhanced through the integration with some nature inspired optimization algorithms such as firefly, particle swarm optimization, genetic algorithm, nomadic people optimizer [53]-[57].

\section{Conclusion}

The current research is conducted on the prediction of the lateral confinement coefficient $\left(K_{s}\right)$ using ANN and SVR models. The models are developed based on gathered dataset from open source researches for the lateral confinement coefficient of columns wrapped with carbon FRP (CFRP). The modeling was performed based on several related parameters including column width, length and thickness $(b, h$ and $t \mathrm{~mm})$, column radius $(r$ $\mathrm{mm})$, compressive strength of concrete $\left(f_{c}^{\prime}\right)$ and elastic modulus $\left(E_{F R P}\right)$. Three modeling scenarios were investigated based on different input combination. The research finding was evidenced the necessity of incorporating all input parameters in building the predictive models. In addition, the performance of the ANN model was demonstrated batter accuracy in comparison with SVR model. Overall, the potential of the soft computing models was exhibited an optimistic methodology for lateral confinement coefficient determination.

\section{Confliect of interest}

The author declares no confliect of interest.

\section{Acknowledgements}

The author is acknowledged his appreciation to the literature review studies where the data of the current research is developed.

\subsection{References}

[1] T. Rossetto and A. Elnashai, "Derivation of vulnerability functions for European-type RC structures based on observational data," Engineering Structures, vol. 25, no. 10, pp. 1241-1263, Aug. 2003.

[2] I. Takewaki, K. Fujita, and S. Yoshitomi, "Uncertainties in long-period ground motion and its impact on building structural design: Case study of the 2011 Tohoku (Japan) earthquake," Engineering Structures, 2013. 
[3] S. Bhagat et al., "Damage to cultural heritage structures and buildings due to the 2015 Nepal Gorkha earthquake," Journal of Earthquake Engineering, vol. 22, no. 10, pp. 1861-1880, 2018.

[4] A. Benavent-Climent, A. Ramírez-Márquez, and S. Pujol, "Seismic strengthening of low-rise reinforced concrete frame structures with masonry infill walls: shaking-table test," Engineering structures, vol. 165, pp. 142-151, 2018.

[5] E. Afsar Dizaj, R. Madandoust, and M. M. Kashani, "Exploring the impact of chloride-induced corrosion on seismic damage limit states and residual capacity of reinforced concrete structures," Structure and Infrastructure Engineering, vol. 14, no. 6, pp. 714-729, 2018.

[6] S. M. Easa and W. Y. Yan, "Performance-Based Analysis in Civil Engineering: Overview of Applications," Infrastructures, vol. 4, no. 2, p. 28, 2019.

[7] W. Ferdous, A. Manalo, T. Aravinthan, and A. Fam, "Flexural and shear behaviour of layered sandwich beams," Construction and Building Materials, 2018.

[8] A. C. Manalo, T. Aravinthan, W. Karunasena, and M. M. Islam, "Flexural behaviour of structural fibre composite sandwich beams in flatwise and edgewise positions," Composite Structures, 2010.

[9] G. Elnabelsy and M. Saatcioglu, "Seismic behavior of concrete bridge columns confined with fiberreinforced polymer stay-in-place formwork," Advances in Structural Engineering, 2018.

[10] Z. M. Yaseen, B. Keshtegar, H.-J. Hwang, and M. L. Nehdi, "Predicting reinforcing bar development length using polynomial chaos expansions," Engineering Structures, vol. 195, pp. 524-535, 2019.

[11] A. A. Mohammed, A. C. Manalo, G. B. Maranan, Y. Zhuge, P. V Vijay, and J. Pettigrew, "Behavior of Damaged Concrete Columns Repaired with Novel FRP Jacket," Journal of Composites for Construction, vol. 23, no. 3, p. 4019013, 2019.

[12] Z. M. Yaseen, H. A. Afan, and M. T. Tran, "Beam-column joint shear prediction using hybridized deep learning neural network with genetic algorithm," in IOP Conference Series: Earth and Environmental Science, 2018.

[13] A. A. H. Alwanas, A. A. Al-Musawi, S. Q. Salih, H. Tao, M. Ali, and Z. M. Yaseen, "Load-carrying capacity and mode failure simulation of beam-column joint connection: Application of self-tuning machine learning model," Engineering Structures, vol. 194, no. November 2018, pp. 220-229, 2019.

[14] A. S. S. Abdullah, M. A. Abed, and I. Al Barazanchi, "Improving face recognition by elman neural network using curvelet transform and HSI color space," Periodicals of Engineering and Natural Sciences, vol. 7, no. 2, pp. 430-437, 2019.

[15] S. R. A. Ahmed, I. Al Barazanchi, Z. A. Jaaz, and H. R. Abdulshaheed, "Clustering algorithms subjected to K-mean and gaussian mixture model on multidimensional data set," Periodicals of Engineering and Natural Sciences, vol. 7, no. 2, pp. 448-457, 2019.

[16] S. F. Jabar, "A classification model on tumor cancer disease based mutual information and firefly algorithm," Periodicals of Engineering and Natural Sciences, vol. 7, no. 3, pp. 1152-1162, 2019.

[17] S. Q. Salih, "A New Training Method based on Black Hole Algorithm for Convolutional Neural Network," Journal of Southwest Jiaotong University, vol. 54, no. 3, 2019.

[18] S. R. A. Ahmed, I. Al Barazanchi, A. Mhana, and H. R. Abdulshaheed, "Lung cancer classification using data mining and supervised learning algorithms on multi-dimensional data set," Periodicals of Engineering and Natural Sciences, vol. 7, no. 2, pp. 438-447, 2019.

[19] M. El Amine Ben Seghier, B. Keshtegar, and B. Elahmoune, "Reliability analysis of low, mid and high-grade strength corroded pipes based on plastic flow theory using adaptive nonlinear conjugate map," Engineering Failure Analysis, p. \#pagerange\#, 2018.

[20] B. Keshtegar and O. Kisi, "RM5Tree: Radial basis M5 model tree for accurate structural reliability analysis," Reliability Engineering and System Safety, 2018.

[21] Z. M. Yaseen and B. Keshtegar, "Limited descent-based mean value method for inverse reliability analysis," Engineering with Computers, vol. 0, no. 0, p. 0, 2018.

[22] H. M. Tanarslan, M. Secer, and A. Kumanlioglu, "An approach for estimating the capacity of RC beams strengthened in shear with FRP reinforcements using artificial neural networks," Construction and Building Materials, 2012.

[23] M. Naser, G. Abu-Lebdeh, and R. Hawileh, "Analysis of RC T-beams strengthened with CFRP plates under fire loading using ANN," Construction and Building Materials, vol. 37, pp. 301-309, 2012.

[24] M. A. Mashrei, R. Seracino, and M. S. Rahman, "Application of artificial neural networks to predict the bond strength of FRP-to-concrete joints," Construction and Building Materials, 2013.

[25] A. Ashrafian, F. Shokri, M. J. T. Amiri, Z. M. Yaseen, and M. Rezaie-Balf, "Compressive strength of 
Foamed Cellular Lightweight Concrete simulation: New development of hybrid artificial intelligence model," Construction and Building Materials, vol. 230, p. 117048, 2020.

[26] S.-P. Zhu, B. Keshtegar, N.-T. Trung, Z. M. Yaseen, and D. T. Bui, "Reliability-based structural design optimization: hybridized conjugate mean value approach," Engineering with Computers, pp. 114, 2019.

[27] J. Li, R. D. Salim, M. S. Aldlemy, J. M. Abdullah, and Z. M. Yaseen, "Fiberglass-Reinforced Polyester Composites Fatigue Prediction Using Novel Data-Intelligence Model," Arabian Journal for Science and Engineering, 2018.

[28] H. Adeli, "Neural networks in civil engineering: 1989-2000," Computer-Aided Civil and Infrastructure Engineering, vol. 16, no. 2, pp. 126-142, 2001.

[29] O. Chaallal, M. Hassan, and M. Shahawy, "Confinement model for axially loaded short rectangular columns strengthened with fiber-reinforced polymer wrapping," ACI Structural Journal, 2003.

[30] L. Lam and J. G. Teng, "Design-oriented stress-strain model for FRP-confined concrete in rectangular columns," Journal of Reinforced Plastics and Composites, 2003.

[31] A. Parvin and W. Wang, "Behavior of FRP jacketed concrete columns under eccentric loading," Journal of Composites for Construction, 2001.

[32] Y. A. Al-Salloum, "Influence of edge sharpness on the strength of square concrete columns confined with FRP composite laminates," Composites Part B: Engineering, 2007.

[33] T. C. Rousakis, A. I. Karabinis, and P. D. Kiousis, "FRP-confined concrete members: Axial compression experiments and plasticity modelling," Engineering Structures, vol. 29, no. 7, pp. 1343 1353, 2007.

[34] M. H. Harajli, E. Hantouche, and K. Soudki, "Stress-strain model for fiber-reinforced polymer jacketed concrete columns," ACI Structural Journal, 2006.

[35] I. A. E. M. Shehata, L. A. V. Carneiro, and L. C. D. Shehata, "Strength of short concrete columns confined with CFRP sheets," Materials and Structures/Materiaux et Constructions, 2002.

[36] T. Turgay, "FRP uygulanmış eksenel yüklü betonarme kolonların davranışı (Behaviour of RC columns confined with FRP)." PhD. Thesis submitted to Y1ldız Teknik Universitesi, 2007.

[37] A. Ilki, O. Peker, E. Karamuk, C. Demir, and N. Kumbasar, "FRP retrofit of low and medium strength circular and rectangular reinforced concrete columns," Journal of Materials in Civil Engineering, 2008.

[38] M. Demers and K. W. Neale, "Strengthening of concrete columns with unidirectional composite sheets," Developments in short and medium span bridge engineering, pp. 895-905, 1994.

[39] S. Pessiki, K. A. Harries, J. T. Kestner, R. Sause, and J. M. Ricles, "Axial behavior of reinforced concrete columns confined with FRP jackets," Journal of Composites for Construction, 2001.

[40] M. Hosotani, K. Kawashima, and J. Hoshikuma, "A study on confinement effect of concrete cylinders by carbon fiber sheets," Non-Metallic (FRP) Reinforcement for Concrete Structures, vol. 1, pp. 209216, 1997.

[41] P. Feng, X. Z. Lu, and L. P. Ye, "Experimental research and finite element analysis of square concrete columns confined by FRP sheets under uniaxial compression," Engineering, 2002.

[42] A. Intelligence, "Fundamentals of Neural Networks Artificial Intelligence Fundamentals of Neural Networks Artificial Intelligence," Fundamentals of Neural Networks : AI Course lecture 37 - 38, notes, slides, 2010.

[43] M. Hameed, S. S. Sharqi, Z. M. Yaseen, H. A. Afan, A. Hussain, and A. Elshafie, "Application of artificial intelligence (AI) techniques in water quality index prediction: a case study in tropical region, Malaysia," Neural Computing and Applications, pp. 1-13, 2016.

[44] I. . Basheer and M. Hajmeer, "Artificial neural networks: fundamentals, computing, design, and application," Journal of Microbiological Methods, vol. 43, no. 1, pp. 3-31, Dec. 2000.

[45] V. Vapnik, The Nature of statistical Learning Theory. New York, NY, USA.: Springer-Verlag New York, Inc., 1995.

[46] C. Cortes and V. Vapnik, "Support-Vector Networks," Machine Learning, vol. 20, no. 3, pp. 273-297, 1995.

[47] Z. M. Yaseen et al., "Prediction of evaporation in arid and semi-arid regions: a comparative study using different machine learning models," Engineering Applications of Computational Fluid Mechanics, vol. 14, no. 1, pp. 70-89, 2019.

[48] Z. M. Yaseen et al., "Stream-flow forecasting using extreme learning machines: A case study in a 
semi-arid region in Iraq," Journal of Hydrology, vol. 542, pp. 603-614, Nov. 2016.

[49] A. Kazem, E. Sharifi, F. K. Hussain, M. Saberi, and O. K. Hussain, "Support vector regression with chaos-based firefly algorithm for stock market price forecasting," Applied Soft Computing, vol. 13, no. 2, pp. 947-958, 2013.

[50] S. Naganna, P. Deka, M. Ghorbani, S. Biazar, N. Al-Ansari, and Z. Yaseen, "Dew Point Temperature Estimation: Application of Artificial Intelligence Model Integrated with Nature-Inspired Optimization Algorithms," Water, 2019.

[51] Z. M. Yaseen, S. M. Awadh, A. Sharafati, and S. Shahid, "Complementary data-intelligence model for river flow simulation," Journal of Hydrology, vol. 567, no. October, pp. 180-190, 2018.

[52] M. A. Ghorbani, R. C. Deo, V. Karimi, Z. M. Yaseen, and O. Terzi, "Implementation of a hybrid MLP-FFA model for water level prediction of Lake Egirdir, Turkey," Stochastic Environmental Research and Risk Assessment, pp. 1-15, 2017.

[53] S. Q. Salih and A. A. Alsewari, "A new algorithm for normal and large-scale optimization problems: Nomadic People Optimizer," Neural Computing and Applications, pp. 1-28, 2019.

[54] H. A. Abdulwahab, A. Noraziah, A. A. Alsewari, and S. Q. Salih, "An Enhanced Version of Black Hole Algorithm Via Levy Flight for Optimization and Data Clustering Problems," IEEE Access, 2019.

[55] S. Q. Salih, A. A. Alsewari, and Z. M. Yaseen, "Pressure Vessel Design Simulation: Implementing of Multi-Swarm Particle Swarm Optimization," in Proceedings of the 2019 8th International Conference on Software and Computer Applications, 2019, pp. 120-124.

[56] S. Q. Salih and A. A. Alsewari, "Solving large-scale problems using multi-swarm particle swarm approach," International Journal of Engineering \& Technology, vol. 7, no. 3, pp. 1725-1729, 2018.

[57] W. Jing et al., "Implementation of evolutionary computing models for reference evapotranspiration modeling: short review, assessment and possible future research directions," Engineering Applications of Computational Fluid Mechanics, vol. 13, no. 1, pp. 811-823, 2019. 